\title{
PATTERN OF INJURIES TO HEART AND ITS MEDICOLEGAL ASPECTS- AN AUTOPSY BASED STUDY
}

\author{
Thankamma P. George1, Vitni Fernz ${ }^{2}$
}

${ }^{1}$ Associate Professor and Deputy Police Surgeon, Department of Forensic Medicine, Government Medical College, Thiruvananthapuram, Kerala, India.

2Junior Resident, Department of Forensic Medicine, Government Medical College, Thiruvananthapuram, Kerala, India.

ABSTRACT
BACKGROUND
Injuries of the chest causing disruption of the thoracic cage and damage to the heart are increasing daily. The anatomic location of
the heart makes it susceptible to trauma. All cardiac injuries have potential to increase the amount of morbidity and mortality with
great medicolegal impact and contribute to $25 \%$ of trauma-related deaths.

\section{MATERIALS AND METHODS}

In this study, we analysed the pattern of cardiac injury and the socio-demographic pattern of the victims in trauma. 250 cases brought to a tertiary care institution for autopsy were studied from $1^{\text {st }}$ January 2005 to $30^{\text {th }}$ November 2005 (1 ${ }^{\text {st }}$ July 2005 - $30^{\text {th }}$

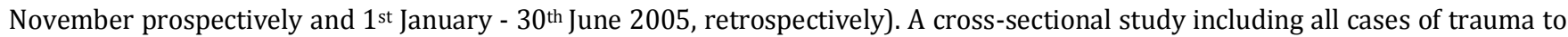
the thorax and heart with consecutive sampling was done. Data was collected in proforma and analysed.

\section{RESULTS}

206 were males (Table 1). Commonest cause of chest injury was trauma. 130 (52\%) were victims of road traffic accidents (Table 2 , Figure 1) and the vehicle implicated the most was bus (41 cases, $16.4 \%$, Table 3, Figure 2). Pedestrians constituted the majority (26.4\%, Table 4, Figure 3). 70.6\% belonged to the working age group (21 - 60 years, Table 5). 104 (41.6\%) were brought dead to the hospital (Table 6). Pericardial injuries were seen in 12 cases, laceration in 7, incised wounds in 3, transfixation and contusion contributed to 1 each (Table 8). Cardiac trauma was seen in 24 cases (9.6\%), comprising contusion in 8 (3.2\%), laceration in $9(3.6 \%)$, cavity terminating in $3(1.2 \%)$, avulsion in $3(1.2 \%)$ and 1 transfixation $(0.4 \%)$ (Table 9). The most commonly affected part of the heart was right ventricle (7 cases, 2.8\%, Table 9, Figure 4) and front surface (6.4\%, Table 10). 5 cases showed haemopericardium (Table 11). In 193 (77.2\%) cases, the cause of death was chest injuries (Table 14, Figure 6).

\section{CONCLUSION}

There is little that the autopsy surgeon can contribute to elucidate the factors leading to accidental deaths. Multiple regression is useful to correlate between predictor and outcome variables. Hopefully, future research will improve the methodology to predict the outcome of cardiac trauma accurately.

\section{KEY WORDS}

Cardiac Injury, Heart, Chest, Trauma, Death.

HOW TO CITE THIS ARTICLE: George TP, Fernz V, Pattern of injuries to heart and its medicolegal aspects- an autopsy based study. J. Evolution Med. Dent. Sci. 2018;7(41):4429-4434, DOI: 10.14260/jemds/2018/989

\section{BACKGROUND}

The technological revolution and man's fascination for modern high-speed vehicles and advancement in the industrial sector increased the frequency of man-made disasters and accidents. Its incidence is fast increasing due to various factors relating to modern civilisation, overpopulation and globalisation. Injuries of the chest with fractures of the ribs and sternum causing disruption of the thoracic cage and often with damage to the lungs, heart and other organs are occurring with increasing frequency in recent times.

Since the bony thoracic cage contains the vital centers of circulation and respiration, trauma to the chest challenges the integrity and even the viability of the entire organism.

'Financial or Other Competing Interest': None.

Submission 27-08-2018, Peer Review 22-09-2018,

Acceptance 29-09-2018, Published 08-10-2018.

Corresponding Author:

Dr. Vitni Fernz,

Krishnasree, MRRA, A-15,

TC 81/4418/1, Thoppil Lane, Vanchiyoor-695035,

Thiruvananthapuram, Kerala, India.

E-mail: vitnifernz@gmail.com

DOI: $10.14260 /$ jemds/2018/989
Cardiac injuries have immense medicolegal and social impact contributing to as much as $25 \%$ of trauma-related deaths to a significant $25 \%$ of all deaths. Most thoracic injuries are attributable to road traffic accidents. All cardiac injuries constitute a potential factor in increasing the amount of morbidity and mortality and therefore proper attention towards their accurate diagnosis and satisfactory management is mandatory. Trauma to the heart can occur due to blunt and sharp forces. Blast injury is another cause.

\section{Chest Injuries can be divided into Two Groups}

1. Non-penetrating or closed chest injuries.

2. Penetrating or open chest injuries.1,2,3

Wilson defined non-penetrating injury of the chest as "one in which the skin and subcutaneous tissue are intact or else if pierced the course of missile or object has been such that neither the pleura nor pericardial sac has been injured and so these spaces have no direct contact with the outside air." Most of the closed chest injuries are caused by blunt force. Penetrating injuries to chest are most commonly the result of stab wounds and are often associated with a range of potentially life-threatening injuries. ${ }^{1}$ 
Both penetrating and non-penetrating injuries can damage the heart. Such a classification does not separate them sharply, since in blunt trauma (non-penetrating injury) the ends of broken ribs and sternum may lacerate the heart and produce the same kind of wound as a sharp object. ${ }^{4}$ Bleeding depends on the site and size of the wound. In general, because of their thinner walls, wounds of the auricles are more dangerous than that of ventricles. For the same reason right ventricular injuries are more dangerous than left ventricular ones. ${ }^{5}$ Other things being equal, the more severe the injury to the thorax and more diseased the heart the more vulnerable it is to trauma. ${ }^{4}$

In World War I, chest wounds in general had a mortality of nearly $60 \%$ with $8 \%$ of such patients dying of cardiac injuries of all types. During World War II, 3.3\% of all thoracic abdominal wounds involved the heart. 6

The spectrum of cardiac injury after blunt chest trauma ranges from clinically insignificant myocardial contusion to full thickness cardiac rupture. Two distinct clinical courses following cardiac injury are reported: acute and subacute. The acute type is due to rupture of a chamber and may lead to death at the site of accident or is fatal a few hours after injury unless treated by surgical intervention. Subacute type as that due to contusion diminishes cardiac reserve placing patients at the risk of death due to cardiac complications remote from the site of injury. ${ }^{7}$ Steering wheel injury is the most typical injury, combining mechanisms of deceleration and compression. The type and extent of blunt thoracic injury vary widely. At one extreme a mild cardiac contusion may be undetected, asymptomatic and resolve spontaneously, whereas at the other end myocardial rupture may occur often resulting in instant death. Injuries to the pericardium, cardiac valves and coronary arteries may produce varied clinical manifestations with differing levels of severity and acuteness. ${ }^{7}$

Occasionally, there can be damage to the heart in an intact chest cage, especially in a child with pliable thorax. Fatal blunt damage of the heart may occur without a mark on the skin of the thorax or on the bony chest cage. Cardiac injuries are usually on the front of the organ, especially to the right ventricle, though posterior bruising and laceration can occur if the heart is compressed against the thoracic spine, as in stamping assault and steering wheel impacts. ${ }^{8}$

\section{There are Three Phenomena occurring in Automobile Collision. 9}

1. Impact of vehicle with a fortuitous object.

2. Reaction of vehicle occupant to the abrupt kinetic forces and the dissipation of such forces by impact environmental deformation and tissue injury which on the cardiovascular system produce contusion, laceration, rupture, commotio cordis and failure.

3. Deceleration of viscera and movement of blood column within the cardiovascular system.

The last two produce bodily injury. The second phenomenon is described as deceleration of occupants against the vehicles interior. In the course this second collision, which occurs milliseconds after the primary one, hydraulic loading can occur due to compression of cardiovascular system. The third collision is described as deceleration of the internal organs, which occurs milliseconds after exterior body decelerates. This sudden deceleration of blood can produce a water hammer effect or a further pressure surge or hydraulic ram effect which is correlated with the magnitude, speed and direction of impact.9,10

\section{Objectives \\ Primary Objective}

To analyse the pattern of injuries to heart and conduct a statistical analysis of victims with cardiac trauma.

\section{Secondary Objectives}

1. To evaluate the nature and intensity of the injuries of heart with a view to find the cause of death.

2. To analyse the medicolegal aspects of cardiac injuries.

\section{MATERIALS AND METHODS}

The study was aimed at analysing the pattern of injuries sustained to the heart following various types of trauma. 250 known dead bodies of both sexes with thoracic injuries brought for medicolegal autopsies to the mortuary of the Department of Forensic Medicine in a tertiary care institution were included in the present study. All cases from $1^{\text {st }}$ July 2005 till $30^{\text {th }}$ November were selected prospectively and from $1^{\text {st }}$ January till $30^{\text {th }}$ June 2005 , retrospectively. Descriptive study design was followed.

A meticulous external examination was made, and details were entered in a proforma. From the autopsy records, the following details were retrieved: Date of death, age and sex of the victim, height and weight of the body. The present investigation included the nature, dimensions and exact location of the injury. Autopsy was conducted by modified Rokitansky's method of in situ dissection in part and en masse removal. As in any medicolegal autopsy, this was done as follows: The skin of the chest wall was reflected on both sides as flaps by cutting through the chest muscles, leaving the ribs bare. In cases of suspected pneumothorax, the skin flap was reflected up to the axilla, creating a pocket, which was filled with water and chest wall punctured through one of the intercostal spaces underwater with a scalpel so that air bubbles pass through if pneumothorax is present. The rib cage was examined for the presence of trauma, its extent and location. The thoracic cavity was then opened by cutting through cartilaginous portions of the ribs using a cartilage knife. The second rib was divided first, about $1 \mathrm{~cm}$ lateral to sternum and then the line of cut extended downwards by cutting the cartilaginous portions of the ribs close to the costochondral junctions. The sternum was lifted up from the mediastinum, but the sternoclavicular joints and first ribs were left intact at this stage. Pleural cavities were examined for the presence of blood or other fluids. The pericardial cavity was also examined. The sternum was retracted anteriorly towards the head to exert tension and the joints were cut by a knife from the posterior aspect, removing the sternal plate. Then, both first ribs were cut. The thoracic and abdominal organs were removed en masse.

All thoracic organs were examined for injury and when present details like nature of injury, locations and dimensions were recorded. Attempt was made to determine the frequency at which the various chambers of the heart were traumatised and to relate the location of heart trauma and the associated bleeding. Photographs were taken wherever possible. 


\section{RESULTS}

Of the 250 cases, 206 were males and 44 were females constituting a sex incidence of $82.4 \%$ and $17.6 \%$ (Table 1 ). The most common cause was trauma and 130 (52\%) were victims of road traffic accidents (Table 2) and the vehicle implicated the most (41 cases, 16.4\%) was bus (Table 3). Pedestrians constituted the majority of the victims $(26.4 \%$, Table 4$)$ and there was male preponderance $(82.4 \%$, Table 1$)$. $70.6 \%$ belonged to the working age group $(21-60$ years, Table 5). $104(41.6 \%)$ were brought dead to the hospital (Table 6). Most of the victims (28.8\%) died within 6 hours of incidence and $37(14.8 \%)$ survived for more than $60 \mathrm{hrs}$ (Table 6). Abrasions were the most common external injuries (34\%, Table 7). Pericardial injuries were seen in 12 cases, laceration in 7 (2.8\%), incised wounds in $3(1.2 \%)$ and transfixation and contusion contributed one each $(0.4 \%$, Table 8). Trauma to the heart was recorded in 24 cases (9.6\%), comprising contusion in $8(3.2 \%)$, laceration in $9(3.6 \%)$, cavity terminating in $3(1.2 \%)$, avulsion in $3(1.2 \%)$ and 1 case of transfixation (0.4\%) (Table 9). The most commonly affected part of the heart was right ventricle (7 cases, $2.8 \%$, Table 9) and front surface (6.4\%, Table 10). 5 cases showed haemopericardium with volume of blood ranging from $100 \mathrm{~mL}$ to $300 \mathrm{~mL}$ (Table 11). The commonest complication was pneumonia (2.4\%, Table 12). In 193 (77.2\%), the cause of death was injuries to the chest (Table 14) and organ combination commonly was head and chest (Table 13, Figure 5). Death was accidental in $84.8 \%$ cases, homicidal in $4.8 \%$, suicidal in $4 \%$, natural in $0.4 \%$ and uncertain in $6 \%$ (Table 15). Similar findings were also observed by Sudheshini Chelayan (1987) (Table 16). ${ }^{10}$

\begin{tabular}{|c|c|c|}
\hline Sex & No. of Cases & Percentage \\
\hline Male & 206 & 82.4 \\
Female & 44 & 17.6 \\
\hline Total & $\mathbf{2 5 0}$ & $\mathbf{1 0 0}$ \\
\hline \multicolumn{2}{|c|}{ Table 1. Sex Distribution of Cases } \\
\hline
\end{tabular}

\begin{tabular}{|c|c|c|}
\hline Cause of Injury & No. of Cases & Percentage \\
\hline Traffic & 130 & 52.0 \\
Fall from height & 46 & 18.4 \\
Stab & 10 & 4.0 \\
Railway occurrence & 27 & 10.8 \\
Fall of heavy objects & 11 & 4.4 \\
Fall from boat & 3 & 1.2 \\
CPR & 4 & 1.6 \\
Blow & 3 & 1.2 \\
Industrial accident & 1 & 0.4 \\
Run over (Road) & 5 & 2.0 \\
Run over (Rail) & 10 & 4.0 \\
\hline Total & $\mathbf{2 5 0}$ & $\mathbf{1 0 0}$ \\
\hline \multicolumn{2}{|c|}{ Table 2. Cause of Trauma to Chest } \\
\hline
\end{tabular}

\begin{tabular}{|c|c|c|}
\hline Vehicle Involved & No. of Cases & Percentage \\
\hline Bus & 41 & 16.4 \\
Lorry & 19 & 7.6 \\
Car & 24 & 9.6 \\
Jeep/ Van & 13 & 5.2 \\
Motor Cycle/ Scooter & 23 & 9.2 \\
Cycle & 2 & 0.8 \\
Train & 26 & 10.4 \\
Auto Rickshaw & 3 & 1.2 \\
Boat & 3 & 1.2 \\
Uncertain & 11 & 4.4 \\
No vehicles & 85 & 34 \\
\hline
\end{tabular}

\begin{tabular}{|c|c|c|}
\hline Total & 250 & 100 \\
\hline \multicolumn{3}{|c|}{ Table 3. Distribution of Vehicles Involved } \\
\hline Position & No. of Cases & Percentage \\
\hline Pedestrian & 66 & 26.4 \\
\hline Motor cyclist & 47 & 18.8 \\
\hline Passenger & 17 & 6.8 \\
\hline Driver (Traffic) & 7 & 2.8 \\
\hline Others & 37 & 14.8 \\
\hline Non-Traffic cases & 76 & 30.4 \\
\hline Total & 250 & 100 \\
\hline 4. Relati & $\begin{array}{l}\text { f Victims } \\
\text { ts }\end{array}$ & ular \\
\hline
\end{tabular}

\begin{tabular}{|c|c|c|c|c|}
\hline \multirow{2}{*}{$\begin{array}{c}\text { Age Group in } \\
\text { Years }\end{array}$} & \multicolumn{3}{|c|}{ No. of Cases } & \multirow{2}{*}{$\%$} \\
\cline { 2 - 4 } & Male & Female & Total & \\
\hline$<10$ & 1 & 1 & 2 & 0.8 \\
$11-20$ & 16 & 4 & 20 & 8 \\
$21-30$ & 36 & 2 & 38 & 15.2 \\
$31-40$ & 30 & 6 & 36 & 14.4 \\
$41-50$ & 43 & 7 & 50 & 20 \\
$51-60$ & 40 & 12 & 52 & 20.8 \\
$61-70$ & 24 & 2 & 26 & 10.4 \\
$71-80$ & 14 & 6 & 20 & 8 \\
$81-90$ & 1 & 4 & 5 & 2 \\
$91<$ & 1 & 0 & 1 & 0.4 \\
\hline Total & 206 & $\mathbf{4 4}$ & $\mathbf{2 5 0}$ & $\mathbf{1 0 0}$ \\
\hline \multicolumn{4}{|c|}{ Table 5. Age Distribution of Cases } \\
\hline \multicolumn{4}{|c|}{}
\end{tabular}

\begin{tabular}{|c|c|c|c|c|c|c|}
\hline \multirow{2}{*}{$\begin{array}{l}\text { Period of } \\
\text { Survival } \\
\text { (In Hours) }\end{array}$} & \multicolumn{2}{|c|}{$\begin{array}{c}\text { Penetrating } \\
\text { Trauma }\end{array}$} & \multicolumn{2}{|c|}{$\begin{array}{c}\text { Blunt } \\
\text { Trauma }\end{array}$} & \multicolumn{2}{|c|}{ Total Cases } \\
\hline & $\begin{array}{l}\text { No. of } \\
\text { Cases }\end{array}$ & & $\begin{array}{l}\text { No. of } \\
\text { Cases }\end{array}$ & & Total & \\
\hline \multirow{9}{*}{$\begin{array}{c}\text { Brought } \\
\text { Dead } \\
<6 \\
6-11 \\
12-23 \\
24-47 \\
48-59 \\
60-72 \\
73-120 \\
121-2880\end{array}$} & 9 & 81.8 & 95 & 39.7 & 104 & 41.6 \\
\hline & 1 & 9.1 & 71 & 29.7 & 72 & 28.8 \\
\hline & 1 & 9.1 & 14 & 5.9 & 15 & 6 \\
\hline & 0 & 0 & 10 & 4.2 & 10 & 4 \\
\hline & 0 & 0 & 7 & 2.9 & 7 & 2.8 \\
\hline & 0 & 0 & 5 & 2.1 & 5 & 2 \\
\hline & 0 & 0 & 9 & 3.8 & 9 & 3.6 \\
\hline & 0 & 0 & 7 & 2.9 & 7 & 2.8 \\
\hline & 0 & 0 & 21 & 15.5 & 21 & 8.4 \\
\hline Total & 11 & 100 & 239 & 100 & 250 & 100 \\
\hline \multicolumn{7}{|c|}{ able 6. Incidence of Period of Survival } \\
\hline
\end{tabular}

\begin{tabular}{|c|c|c|}
\hline Injury & No. of Cases & Percentage \\
\hline Abrasion & 85 & 34 \\
\hline Contusion & 33 & 13.2 \\
\hline Laceration & 1 & 0.4 \\
\hline Combination of injuries & 64 & 25.6 \\
\hline No injury & 67 & 26.8 \\
\hline Total & 250 & 100 \\
\hline \multicolumn{3}{|c|}{ Table 7. Distribution of External Injuries } \\
\hline
\end{tabular}

\begin{tabular}{|c|c|c|}
\hline Injury & No. of Cases & Percentage \\
\hline Contusion & 1 & 0.4 \\
Laceration & 7 & 2.8 \\
Incised wound & 3 & 1.2 \\
Transfixation & 1 & 0.4 \\
No injury & 238 & 95.2 \\
\hline Total & $\mathbf{2 5 0}$ & $\mathbf{1 0 0}$ \\
\hline \multicolumn{2}{|c|}{ Table 8. Frequency of Pericardial Injury } \\
\hline
\end{tabular}




\begin{tabular}{|c|c|c|c|c|c|c|c|}
\hline 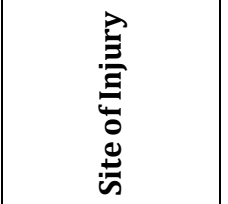 & 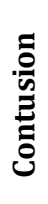 & & 茪 & 总 & $\frac{5}{3}$ & $\begin{array}{l}\text { 표 } \\
0 \\
0\end{array}$ & de \\
\hline RA & 2 & 0 & 0 & 0 & 0 & 2 & 0.8 \\
\hline LA & 0 & 1 & 0 & 0 & 0 & 1 & 0.4 \\
\hline $\mathrm{LV}$ & 1 & 1 & 1 & 1 & 0 & 4 & 1.6 \\
\hline RV & 3 & 2 & 2 & 0 & 0 & 7 & 2.8 \\
\hline RA, LA, LV+RV & 0 & 1 & 0 & 0 & 2 & 3 & 1.2 \\
\hline $\mathrm{RA}+\mathrm{LA}$ & 0 & 1 & 0 & 0 & 0 & 1 & 0.4 \\
\hline$R A+R V$ & 0 & 1 & 0 & 0 & 0 & 1 & 0.4 \\
\hline $\mathrm{LA}+\mathrm{LV}$ & 0 & 1 & 0 & 0 & 0 & 1 & 0.4 \\
\hline $\mathrm{RV}+\mathrm{LV}$ & 0 & 1 & 0 & 0 & 1 & 2 & 0.8 \\
\hline $\begin{array}{c}\text { Atrioventricular } \\
\text { junction }\end{array}$ & 1 & 0 & 0 & 0 & 0 & 1 & 0.4 \\
\hline $\begin{array}{c}\text { Interventricular } \\
\text { junction }\end{array}$ & 1 & 0 & 0 & 0 & 0 & 1 & 0.4 \\
\hline No injury & 0 & 0 & 0 & 0 & 0 & 226 & 90.4 \\
\hline Total & 8 & 9 & 3 & 1 & 3 & 250 & 100 \\
\hline
\end{tabular}

\begin{tabular}{|c|c|c|}
\hline Site & No. of Cases & Percentage \\
\hline Front & 16 & 6.4 \\
\hline Back & 2 & 0.8 \\
\hline Border & 1 & 0.4 \\
\hline Front to Back & 5 & 2 \\
\hline No injury & 226 & 90.4 \\
\hline Total & $\mathbf{2 5 0}$ & $\mathbf{1 0 0}$ \\
\hline Table 10. Distribution of Injuries to Surface of Heart \\
\hline
\end{tabular}

\begin{tabular}{|c|c|c|}
\hline Quantity of Blood & Number & Percentage \\
\hline No Blood & 245 & 98 \\
\hline $100 \mathrm{~mL}$ & 1 & 0.4 \\
\hline $150 \mathrm{~mL}$ & 2 & 0.8 \\
\hline $200 \mathrm{~mL}$ & 1 & 0.4 \\
\hline $300 \mathrm{~mL}$ & 1 & 0.4 \\
\hline Total & 250 & 100 \\
\hline \multicolumn{3}{|c|}{ Table 11. Incidence of Haemoperi } \\
\hline
\end{tabular}

\begin{tabular}{|c|c|c|}
\hline Complications & No. of Cases & Percentage \\
\hline Meningitis & 1 & 0.4 \\
Pneumonia & 6 & 2.4 \\
Septicaemia & 3 & 1.2 \\
Pneumonia + Septicaemia & 3 & 1.2 \\
No complications & 237 & 94.8 \\
\hline \multicolumn{2}{|c|}{ Table 12. Complications } \\
\hline
\end{tabular}

\begin{tabular}{|c|c|c|}
\hline Organs Involved & $\begin{array}{c}\text { Number of } \\
\text { Cases }\end{array}$ & Percentage \\
\hline Head + Chest & 53 & 21.2 \\
\hline Neck + Other organs & 32 & 12.8 \\
\hline Chest + Abdomen & 20 & 8 \\
\hline Head + Neck & 13 & 5.2 \\
\hline Chest + Head + Abdomen & 20 & 8 \\
\hline Head + Left Lower Limb & 7 & 2.8 \\
\hline Other Combinations & 87 & 34.8 \\
\hline No Extrathoracic Injuries & 18 & 7.2 \\
\hline Total & 250 & 100 \\
\hline \multicolumn{3}{|c|}{ Table 13. Organ Combinations } \\
\hline
\end{tabular}

\begin{tabular}{|c|c|c|}
\hline Cause of Death & No. of Cases & Percentage \\
\hline Chest injury alone & 13 & 5.2 \\
\hline Chest + Other injuries & 193 & 77.2 \\
\hline Other injuries without chest & 30 & 12 \\
\hline Chest injury + drowning & 3 & 1.2 \\
\hline Infection following injury & 6 & 2.4 \\
\hline Natural & 1 & 0.4 \\
\hline Drowning & 2 & 0.8 \\
\hline Tension pneumothorax & 1 & 0.4 \\
\hline Drowning + other injuries & 1 & 0.4 \\
\hline Total & 250 & 100 \\
\hline \multicolumn{3}{|c|}{ Table 14. Cause of Death } \\
\hline
\end{tabular}

\begin{tabular}{|c|c|c|}
\hline Manner of Death & No. of Cases & Percentage \\
\hline Accident & 212 & 84.8 \\
Homicide & 12 & 4.8 \\
Suicide & 10 & 4.0 \\
Natural & 1 & 0.4 \\
Uncertain & 15 & 6.0 \\
\hline \multicolumn{2}{|c|}{ Total Table 15. Manner of Death } \\
\hline
\end{tabular}

\begin{tabular}{|c|c|c|c|}
\hline Author & Year & $\begin{array}{c}\text { Cardiac } \\
\text { Injury/Total }\end{array}$ & \% \\
\hline Barber & 1942 & $8 / 33$ & 24.2 \\
Sigler & 1945 & $32 / 42$ & 76.2 \\
Watson & 1960 & $17 / 44$ & 38 \\
Dolora & 1967 & $19 / 98$ & 19 \\
Jones & 1975 & $45 / 210$ & 21 \\
Potkin & 1982 & $70 / 100$ & 70 \\
Kron & 1983 & $7 / 50$ & 14 \\
Sutherland & 1983 & $15 / 77$ & 19 \\
Harley & 1984 & $21 / 74$ & 28 \\
Sudeshini & 1987 & $21 / 200$ & 10.5 \\
\hline Table 16. Incidence of Cardiac Injury in Blunt Chest \\
\multicolumn{4}{|c}{ Trauma }
\end{tabular}

\section{DISCUSSION}

Thoracic injuries are one of the important causes of mortality in accidents. Its incidence is fast increasing due to various factors relating to modern civilisation and globalisation. The fast-increasing incidence can be explained by lack of proper planning and failure to develop infrastructure to cope up with the hazards of modern way of lifestyle. Majority of the victims of thoracic trauma are due to traffic accidents.

In this investigation undertaken at the Department of Forensic Medicine at a tertiary care institution, an earnest attempt was made to study the pattern of cardiac injuries and various socio-demographic variables related to them. The study was done for a period from January $1^{\text {st }} 2005$ to November $30^{\text {th }} 2005$. The total numbers of cases studied were 250. In the present series it was observed that males dominated, constituting $82.4 \%$ as compared to females. The dominance of males is readily explainable by the fact that males are more exposed to hazards of roads, industry, violence and sports as they constitute working and earning member in majority of the families.

It was observed that majority of the cases were in the age group of $51-60$ years (20.8\%) followed by 41 - 50 years (20\%). A systematic evaluation of the survival period has been carried out and we found that the survival period of a victim after sustaining injury varied from spot death to about four months. 104 victims were brought dead (41.6\%). Majority of thoracic injuries were non-penetrating (95.6\%), out of which the maximum number $(52 \%)$ was due to 
vehicular accidents. One case $(0.4 \%)$ was found with external injuries without any internal thoracic injury. Involvement of rib alone constituted 93 cases (37.2\%) followed by combination of rib and lung 54 cases (21.6\%), rib and sternum 13 cases (5.2\%), sternum and lung 12 cases (4.8\%). Various other organs were involved in 67 cases (26.8\%). Both contusion and laceration of the pericardium may occur with blunt injuries. Pericardial injury was noted in 12 cases with 7 cases $(2.8 \%)$ of laceration and 3 cases $(1.2 \%)$ of incised wounds, while transfixation and contusion was noted in one case each $(0.4 \%)$.

For centuries, all heart injuries were considered fatal and only in the last century was this tenet disproved. Cardiac trauma has been categorised classically as being either penetrating or blunt. The chest wall offers little protection from penetration, often making these wounds lethal with the majority of patients dying before arrival at trauma care units. The heart is vulnerable to both blunt and penetrating injuries. In our investigation, trauma to the heart was observed in 24 cases (9.6\%). Previous study by Dr. Sudeshini Chelayan (1987) supports our findings (10.5\%). ${ }^{10}$ Clinical blunt trauma studies have demonstrated wide variations in incidence ${ }^{6}$ and wide differences in selection criteria for detecting cardiac injury have made comparisons difficult. Right ventricle was affected in 7 cases $(2.8 \%)$ and left ventricle in 4 cases $(1.6 \%)$. Right atrium was affected in 2 cases $(0.8 \%)$, while left atrium was afflicted in 1 case $(0.4 \%)$ only. Interventricular junction and atrioventricular junction were affected in 1 case each. Majority of the injuries was on the front aspect of the heart $16(6.4 \%)$. Penetrating injuries were observed in 4 cases $(1.6 \%)$ and blunt injuries in 20 cases (8\%).

The medical implications of contusive heart injury are obvious, unless the possibility of contusive heart injury is fully explored in such instances by the attending physician with appropriate diagnostic study a potentially lifethreatening condition will go unrecognised. The legal implications of traumatic heart injury from non-penetrating chest trauma revolves about the questions of diagnosis, disability evaluation causality and prognosis.

Moritz (1954) stated that the auricles bleed more than the ventricles due to their thinner walls and for the same reason the right ventricular injuries bleed more than the left ventricular one and our observations are in agreement with the above statement. ${ }^{5}$ Haemopericardium was observed in 5 cases only (2\%); 3 due to penetrating injury and 2 were due to blunt force injury. In our present investigation of the 250 cases with thoracic injuries, 212 cases (84.8\%) were due to accidents. The cause of death is of prime significance for the forensic pathologist, legal justice system and law enforcement agencies. Out of the 250 cases investigated with injuries, in 193 (77.2\%) cases the cause of death was injuries of chest and other combinations.

\section{CONCLUSION}

The importance of autopsy in trauma research has been widely accepted the world over and the present investigation was undertaken to focus light upon the pattern of thoracic injuries in relation to various factors. A total number of 250 cases were studied from $1^{\text {st }}$ January 2005 to $30^{\text {th }}$ November 2005. The results are summarised as follows:

1. Majority of the victims was male (82.4\%).

2. $70.6 \%$ belonged to the working age group of $21-60$ years and were most commonly involved in trauma cases.
3. 104 victims $(41.6 \%)$ were brought dead. Most of the victims $(72 ; 28.8 \%)$ died within 6 hours of incidence and 37 (14.8\%) survived for more than $60 \mathrm{hrs}$. The period of survival has not shown an increase despite the advancement of trauma care units due to delay in bringing the victim to casualty.

4. Pericardial injuries occurred in 12 cases, laceration in 7 (2.8\%), incised wounds in $3(1.2 \%)$, transfixation and contusion in one each $(0.4 \%)$.

5. Cardiac injuries were reported in 24 cases. Right ventricle was most commonly affected ( 7 cases, $2.8 \%$ ).

Unfortunately, but realistically speaking, there is little that the autopsy surgeon can contribute to the elucidation of factors leading to accidental deaths. In our investigations, due to the constraints of time and other related factors, we opted for the familiar form of analysis which describes the linear relationship between two variables. Multiple regression is a technique in which more than one independent variable is used to describe a single, continuous variable and is advantageous because it allows one to measure the association between a predictor variable and an outcome variable. Continued future research hopefully will improve the methodology to predict the outcome of cardiac trauma accurately.

\section{PROFORMA}

1. Serial number:

2. Date:

3. Age:

4. Sex:

5. Height:

6. Weight:

7. Nutritional status:

8. Occupation:

9. History of previous illness if any:

10. History of the case:

11. Clinical history if available:

12. Details of treatment given:

13. Survival time:

14. Cause of injury:

a) Automobile accident: Traffic (P) Traffic (D)

b) Fall from height:

c) Fall from a running vehicle:

d) Kicks:

e) Blows:

f) Stab injury:

g) Industrial accident:

h) Run over by vehicle:

i) Rail traffic accident:

j) Others:

15. External injuries:

16. Organs injured:

17. Part of heart injured:

18. Wall of heart injured:

19. Type of injury to heart:

20. Pericardial injury:

21. Complications:

22. Combination of injuries:

23. Cause of death:

24. Manner of death: 


\section{REFERENCES}

[1] Gordon I, Shapiro HA. Forensic Medicine: a guide to principles. $2^{\text {nd }}$ edn. London: Churchill Livingstone 1982: p. 301-10.

[2] Umadethan B. Practical Forensic Medicine: a guide to medicolegal practice. $2^{\text {nd }}$ edn. Thiruvananthapuram: RV Publications 1994: p. 172.

[3] Reddy NKS. The essentials of forensic medicine and toxicology. 34th edn. Om Sai Graphers 2017.

[4] Gonzales TA, Monganvances, Helpner M, et al. Legal medicine and toxicology. Newyork: D. Appleton Century Company 1940: p. 115-28.

[5] Moritz AR. The pathology of trauma. $2^{\text {nd }}$ edn. Lee \& Febiger 1954: p. 1-76, 133-222.
[6] Moylan JA. Trauma \& Surgery. Philadelphia: JB Lippincott Company 1792: p. 77-195.

[7] Dalvi AN, Gondhalekar RA, Shirhatti RG, et al. Atrial rupture following blunt chest trauma. Journal of Postgraduate Medicine 1987;33(3):152-4.

[8] Knight B. Forensic Pathology. 2nd edn. London: Edward Arnold 1996: p. 198-206.

[9] Lasky II. Forensic aspects of traumatic non penetrating heart disease - Medicine, Science and the Law. Vol. 6. London: Sweet \& Maxwell 1966: p. 132-41.

[10] Chellayan S. Study of the medical aspects of injuries to thorax. Thesis submitted to the University of Kerala for MD (Forensic Medicine) Exam. 1987. 